\title{
The oscillating body: an enactive approach to the embodiment of emotions*
}

\author{
O corpo oscilante: uma abordagem enativista ao \\ embodiment das emoções
}

CARLOS VARA SÁNCHEZ

\begin{abstract}
The aim of this paper is to advance, within the framework of enactivism, towards a more radically embodied and situated theory of emotions and, in general, of affectivity. Its starting point is that of discussing the well-established notion of bodily resonance (Fuchs 2013, Fuchs \& Koch 2014, Fuchs 2018) and the primordial affectivity approach (Colombetti 2014). I will incorporate John Dewey's theory of emotions, and recent models and empirical finding from cognitive science on the relation between perception and bodily activity (Azzalini, Rebollo \& Tallon-Baudry 2019; Allen et al. 2019). The novel element proposed in this paper is taking into consideration the role of bodily oscillatory activity in the perceptual side of cognition through phenomena of relative coordination. This concept from dynamical systems theory allows for an enactivist view of emotions as temporal episodes triggered by a tension that affects the rhythmic interaction between brain, body, and environment. By defending the importance of this enacted rhythm, the body emerges as a truly active agent, gating and modulating affectivity during all the stages of the sensorimotor circuit from perception to action.
\end{abstract}

Keywords: Enactivism. Embodiment. Emotions. Oscillatory activity. Dewey.

\footnotetext{
* This result is part of a project that has received funding from the European Union's Horizon 2020 research and innovation programme under the Marie Sklodowska-Curie grant agreement No 794484.

The paper reflects only the author's view and the Research Executive Agency is not responsible for any use that may be made of the information it contains.

a Ca' Foscari University, Venice, Italy. Phd in Humanities, e-mail: carlos.varasanchez@unive.it
} 


\section{Resumo}

O objetivo do presente artigo é avançar, no âmbito da estrutura da enação, para uma teoria das emoções - e em geral da afetividade - mais radicalmente incorporada $e$ estabelecida. Seu ponto de partida é a discussão da noção bem estabelecida de ressonância corporal (Fuchs 2013, Fuchs \& Koch 2014, Fuchs 2018) e a abordagem da afetividade primordial (Colombetti 2014). A teoria das emoções de John Dewey $e$ modelos recentes e descobertas empíricas da ciência cognitiva na relação entre percepção e atividade corporal serão incorporadas (Azzalini, Rebollo \& Tallon-Baudry 2019; Allen et al. 2019). O novo elemento proposto neste artigo é levar em consideração o papel da atividade oscilatória corporal no lado perceptivo da cognição através de fenômenos de coordenação relativa. Este conceito da teoria dos sistemas dinâmicos permite uma perspectiva de enação das emoções como episódios temporais desencadeados por uma tensão que afeta a interação rítmica entre o cérebro, o corpo e o ambiente. Defendendo a importância desse ritmo executado, o corpo emerge como um agente verdadeiramente ativo, obstruindo e modulando a afetividade durante todos os estágios do circuito sensório-motor, da percepção à ação.

Palavras-chave: Enativismo. Encarnação. Emoções. Atividade oscilatória. Dewey.

\section{Introduction}

The limits and the implications of the role of emotions at the crossroads between the body, the brain, and the environment, as well as its alleged mediation between perception and action, continue to be debated. This paper will focus, specifically, on the range and the nature of the roots of the embodiment of emotions. Although there is plenty of literature on this topic, it remains to be a controversial issue. Many theories of emotion have historically proposed the body to carry some relevance. However, among those that can be considered nowadays as the most relevant philosophical theories of emotion-i.e. cognitivism, perceptual model, and emotions as bodily experiences ${ }^{1}$ — there are relevant differences in the scope and the influence of this bodily component on the origin, effect, and experience of emotions. Between these groups, the third one is not constrained by mentally evaluative concepts such as appraisal, but presents the body as a constitutive feature of our

\footnotetext{
${ }^{1}$ An explanation of this classification can be found in Laura Candiotto's entry "Emotions" for the Encyclopedia of Educational Philosophy and Theory (Candiotto 2016).
} 
emotional and affective being in the world. Among the approaches appertaining to this group, which underline an embodied and embedded concept of mind, there is the one that will structure this paper: enactivism².

In the following pages, I will establish a triangular conceptual framework in which every point will be related to the other two, generating their own tensions and connections. Those points will be the following:

1. Relevant current enactivist theories of emotions, namely the primordial affectivity approach (Colombetti 2014) and the notion of bodily resonance (Fuchs 2013, Fuchs \& Koch 2014, Fuchs 2016).

2. John Dewey's theory of emotions. Pragmatist ideas, mainly those presented by William James, are still highly influential in philosophy of emotions; however, some of these conceptual lines, which were developed by some fellow pragmatists such as John Dewey (Dreon 2019), do not enjoy as much attention. This fact and the acknowledgement of pragmatism as forerunner of enactivism, justify an exploration of the relation of some pertinent Deweyan notions in relation with the theories mentioned in (1).

3. Empirical findings and theoretical models on the influence of bodily oscillatory activity (gastric, respiratory, heart rate frequency) upon cognition.

The main goal of this paper, following the encouragement of this special issue to discuss new approaches in the field of philosophy of emotions, is exploring the role of the dynamics of oscillatory patterns between brain and body in our affective engagement with the world. I will focus in the particular rhythmicity of relative coordination between brain and body oscillatory activity as a potential constitutive element of the embodiment of emotions. Embodiment as a dynamic process, active

\footnotetext{
${ }^{2}$ Enactivism is a branch of embodied approaches to cognition (i.e. all enactivism is embodied, but not all embodied approaches are enactivist) which defends a dynamical, sensorimotor, non-dualistic, non-representational, embodied and situated view of cognition. Enactivism often combines philosophy of mind and cognitive science empirical findings in order to establish models, theories and approaches. For some introductory but relevant readings on enactivism see Varela et al. 1991; O'Regan \& Noë 2001; Gallagher 2017.
} 
and passive, that takes place from the very start of our perceiving the world while conditioning our actions.

\section{Enactive emotions}

One common issue within philosophy of emotions is that of committing to a general definition of emotions. In this paper I will work within the notion of emotions as "complex states of mind and body, which have an active power-they are not characterized only as receptivity — that impacts human's intentionality towards the environment" (Candiotto 2016). What I find particularly appealing of this definition is its triple mediational character. Emotions as relating to mind and body, passivity and activity, agent and environment. Emotions, therefore, become non-dualist fluid patterns at the roots of cognition. Even if not explicitly acknowledged when published, I consider Candiotto's definition to be absolutely aligned with enactivism and, as consequence, pertinent to my intentions in this paper.

Giovanna Colombetti, in her book The feeling body: Affective science meets the enactive mind, develops the notion of "primordial affectivity". Affectivity, according to her theory, appeared evolutively even before than the simplest form of consciousness; it is the inescapable way in which an embodied organism engages with the environment (Colombetti 2014: 22). On the ground of the enactive tenet of the continuity of mind and life (Thompson 2007), she concludes that "affectivity is a pervasive dimension of the mind, deeper and broader than the emotions and moods of the affective scientist" (Colombetti 2014: 203). If we take away affectivity from our notion of cognition we are taking the body away as well, and, as a consequence, we are no longer considering cognition in itself, but as an opaque immaterial shadow unable to engage and be engaged, effectively, by the world and its inhabitants. That way, embodiment becomes a sort of synonym of affectivity; saying that cognition is embodied is the same as saying that is affective. There is no potential compromise. If we defend that cognition is embodied, it necessarily has to be affective, and the other way around.

Within this affective sea in which we navigate, according to Colombetti, we can traverse diverse climate zones with their specific long-standing conditions (moods) and briefer specific weather patterns (emotions) (Colombetti 2014: 78-79). We are always in an affective rapport with the environment and, at the same time, we 
are subject to moods which, in turn, afford us certain fleeting emotions. From her point of view, emotions are best characterized as dynamical self-organizing patterns of the organism (Colombetti 2014: 53). That is, if enactivism views cognition as time extended, dynamically evolving, and constrained by and enacting multiple interactions between brain, body, and environment, "emotional episodes are context dependent, flexible, and 'loosely assembled' and yet can also display stability across contexts" (Colombetti 2014: 57). Thus, according to Colombetti, emotional episodes should be considered as self-emergent coordinative structures "likely to entrain [the somatic system] into specific configurations that depend on external as well as internal constraints" (Colombetti 2014: 62). Colombetti explicitly adopts and echoes the terminology and some concepts of dynamical system theory-i.e. entrain, constraint- to defend that

\footnotetext{
Regions of stability (attractors) within the state space pull variously constituted emotion forms toward or away from them. The presence of these regions guarantees relative stability in spite of variations, and the capacity of various processes (neural, muscular, etc.) to influence and constrain one another allows stability to be achieved in various ways (Colombetti 2014: 70).
}

She gets to the brink of offering a dynamic oscillatory theory of affectivity, for she defends that "changes in moods shift the landscape of attractors and repellors, pulling or 'enslaving' brain and bodily processes more toward certain emotion forms than others" (Colombetti, 2014: 78). Colombetti offers a brilliant general framework of the nested interaction of moods and emotions in the context of embodied cognition. However, in order to explore in more detail some specific mechanisms beyond the embodiment of cognition in emotional episodes, I will introduce Thomas Fuch's use of the Jamesian concept of bodily resonance.

Thomas Fuchs has recently described emotions as "circular or feedback relation between a living being and its present situation with its particular affective qualities, values, and affordances_as a cycle of embodied affectivity" (Fuchs 2018: 122). He presents a model of emotions that underlines their nature as simultaneously situated and embodied events. On the one hand, they are situated because they "emerge as specific forms of a subject's bodily directedness towards the affective quality and values of a given situation. They encompass subject and situation and therefore may not be localized in the interior of persons" (Fuchs 2018: 123). On the other hand, emotions are embodied because they imply different components of 
bodily resonance. Bodily resonance is considered the way we experience emotions, for " $[\mathrm{b}]$ odily resonance acts as the medium of our affective engagement in a given situation" (Fuchs and Koch 2014: 4). Fuchs draws as well on the notion of the body as "sounding-board" developed by William James"3; however, to the best of my understanding, the notion of bodily resonance, as understood by Fuchs, seems to be mainly focused on the phenomenological notion of the "lived body" [Leib] introduced by Edmund Husserl in the second volume of the Ideas (1989), and not much on that of the "physical body" [körper]. For Fuchs bodily resonance

includes all kinds of local or general bodily sensations: feelings of warmth or coldness, tickling or shivering, pain, tension or relaxation, constriction or expansion, sinking, tumbling or lifting, etc. There is no emotion without at least the slightest bodily sensations and movement tendencies (Fuchs 2016: 196).

Accordingly, bodily resonance is essentially a mediational feature to engage with the affective affordances of the environment (Fuchs 2018: 124). Fuchs defends the coexistence of two components of bodily resonance: centripetal or affective component and centrifugal or 'emotive' component"; however, the bodily resonance seems to be rather passive: a membranous feature of the body that reverberates to certain inputs from the environment, affecting our perception of an event ${ }^{5}$, and favoring certain actions (Fuchs 2018: 123). Although I am extremely sympathetic to Fuchs's brilliant and enlightening model, I cannot help to notice a qualitative

3 "[O]bjects do excite bodily changes by a preorganized mechanism, or the farther fact that the changes are so indefinitely numerous and subtle that the entire organism may be called a sounding-board, which every change of consciousness, however slight, may make reverberate. The various permutations and combinations of which these organic activities are susceptible make it abstractly possible that no shade of emotion, however slight, should be without a bodily reverberation as unique, when taken in its totality, as is the mental mood itself. The immense number of parts modified in each emotion is what makes it so difficult for us to reproduce in cold blood the total and integral expression of any one of them" (James 1890).

4 "A centripetal or affective component, that is, being affected, "moved," or "touched" by an event through various forms of bodily sensations (e.g., the already mentioned blushing and burning of shame). This resonance in turn influences the affective perception of the situation- for example, feeling one's heart beat and a shortness of breath increases the frightening impression of a dangerous situation. A centrifugal or "emotive" component, that is, a bodily action readiness, implying specific tendencies of movement (e.g., hiding, avoiding the other's gaze, "sinking into the floor" from shame; flight reaction in anxiety). In emotions, we are moved to move (SheetsJohnstone 1999) (emovere = to move out)" (Fuchs 2018: 123).

5 "[R]esonance in turn influences the affective perception of the situation -for example, feeling one's heart beat and a shortness of breath increases the frightening impression of a dangerous situation" (Fuchs 2018: 123). 
difference between his and Colombetti's approaches. While Colombetti, following dynamical system theory, speaks of emotions as loosely assembled, self-emergent, coordinative structures, Fuchs seems to favor a much more modular model in which bodily resonance is a structural feature of the body, with bodily feelings and action tendencies working, respectively, as the afferent and the efferent pathways or the embodiment of emotions. He backs his claims with research suggesting that a "hardening" or lack of resonance -i.e. impaired processing of interoceptive signalscorrelates with reduced intensity of emotions, and, conversely, increasing bodily resonance implies an amplified emotional attitude towards the environment (Fuchs 2018: 125). However, I think that this idea of emotion lacks certain "active power" deemed necessary by Candiotto's definition that we previously adopted. The conceptualization of the body as an anvil played by the hammer of the environment, whose reverberations influence how we engage back with it ${ }^{6}$ presents the body at a precise place; namely, the end of the road of the sensory and the starting of action, almost depleted of initiative.

Despite Fuch's and Colombetti's agreement on the radically embodied nature of emotions, there appears to be differences in the way this embodiment takes place. My interpretation of Fuch's concept of resonance is that it presents predominant connotations of passivity that, at best, hardly fulfils enactivist's claims on the constitutive role of the body in cognition, and, at worst, borders with dualism. For that reason I intend to combine Colombetti's outlined notion of emotional episodes with some of Fuch's ideas of bodily resonance, trying to expand them from their modular placement into a much more dynamic notion of emotions. This will be attempted by resorting to John Dewey's theory of emotions and research on the oscillatory coordination between brain, body, and environment.

\section{Between tension and coordination}

William James is an undisputed influence on contemporary philosophy of emotions; however, I agree with Roberta Dreon when she defends that advances can

\footnotetext{
${ }^{6}$ In Fuchs and Koch's words bodily resonance "imbues, taints and permeates the perception of this situation without necessarily stepping into the foreground" (Fuchs \& Koch 2014: 4).
} 
be made by taking into consideration James's theories as part of "open laboratory for ideas and hypotheses" further continued by the work of pragmatists such as George Herbert Mead and John Dewey (Dreon 2019). In the case of this paper I will mainly focus on one aspect of Dewey's theory of emotions: the tension in the coordination during emotional episodes. With this somehow obscure notion I intend to connect the intuitions of the sheer dynamical self-constituent embodied nature of emotions of Colombetti's "primordial affectivity" and foster the active side of Fuch's bodily resonance.

Dewey's theory of emotions was laid down in two early papers published in the span of few months (Dewey 1894; Dewey 1895) and a third one on the Reflex Arc Concept (Dewey 1896), which contains the relevant notion of "organic circuit". He built his theory upon those of Charles Darwin and William James ${ }^{7}$, while incorporating several novel aspects which, nowadays, are still open to debate. One of these is his idea of perception as necessarily emotional. For him, there are no separated phases -a cognitive one first, and an emotional one afterwards. Perception is always situated, aimed at action, and emotional. Only retrospectively can we judge the conceptual features of perception from an isolated standpoint. In order to explain his point of view, Dewey added a twist to James's classic example of the bear (James 1890: 449-450). According to Dewey we actively perceive the bear as a fearful object; that is,

it is not the idea of the bear, or the bear as object, but a certain act of seeing, which by habit, whether inherited or acquired, sets up other acts. It is the kind of coordination of acts which, brought to sensational consciousness, constitutes the bear a fearful or a laughable or an indifferent object (Dewey 1895: 19).

The implications of this paragraph are enormous. The idea of the "act of seeing" as the cornerstone of the embodiment of emotions intertwines neatly perception and action, escaping both from dualism and from the notion of the body as passive receptor of information from the environment. Dewey defends that the coordination of acts, which causes the mode of behavior, contains an inherent tension

\footnotetext{
${ }^{7}$ For a thorough analysis of the general ideas of Dewey's theory of emotion and its relation with those of Darwin and James see Garrison 2003 and Dreon 2012.
} 
between the stimulus and the response (Dewey 1895: 18-19). This "tension" is of such significance for Dewey as to define emotion as "psychologically, the adjustment or tension of habit and ideal and the organic changes in the body are the literal working out, in concrete terms, of the struggle of adjustment" (Dewey 1895: 30). The idea of emotion as a disturbance between what Dewey calls the "vegetative-motor" function (e.g. heart frequency, gastric activity, respiration) and the "sensori-motor" (e.g. hearing, seeing, touching, smelling, tasting) firmly anchors the role of the body as constitutive in the enactment of emotions. Embodiment becomes inescapable; but not only that, he points towards a self-regulated mechanism between brain and body as that which guides the evolution of the emotional episode. The tension would be the starting of the emotional episode, and of its evolution depends the magnitude and the outcome of the experience. This idea of Dewey seems to, somehow, anticipate not only some of Colombetti's aforementioned ideas, but Gallagher and Micah Allen's views on the role of perception in Predictive Engagement ${ }^{8}$ :

In perception bodily affective changes are integrated with sensory-motor processing so that before we fully recognize an object or other person for what it or he or she is, our bodies are already configured into overall peripheral and autonomic patterns shaped by prior associations. This implies, first, that perception is not just for recognition or identification [...] Nor is perception just for action [...] Perception is also reward-oriented, hedonic, aesthetic, and affective in the broadest sense [...] [P]erceptual networks are dynamically connected to and (both in terms of those connections, and in terms of plastic changes) affected by deeply embodied processes that involve endocrine and autonomic systems (Gallagher \& Allen 2018: 2636-2637).

I think that the previous lines, in enactivist vocabulary, relate nicely to some of Dewey's ideas, while opening the door to the possibility of exploring the dynamic and active aspects of the embodiment of emotions beyond the conceptualization of bodily resonance. Whereas Fuchs speaks of bodily resonance as an influence in cognition, following Dewey, I propose explore embodiment as already playing a constitutive role at the very start of the engagement with a new stimulus.

\footnotetext{
${ }^{8}$ Predictive engagement is an enactivist-coherent version of predictive processing theories. They propose thinking of processes as a kind of "ongoing predictive engagement (PE) -a dynamical adjustment in which the brain, as part of and long with the larger organism, actively responds in ways that allow for the right kind of ongoing attunement with the environment- an environment that is physical but also social and cultural (Gallagher \& Allen 2018: 2634).
} 
Acknowledging the role of our body in the enactment of sensorimotor patterns that condition every experience. And taking into consideration the punctual inhibition of this immediate coordination between perception and action as the triggering of the disturbance of an emotion. Or, in more enactivist words, an emotion starts with a destabilization of sensorimotor agency ${ }^{9}$. I understand this destabilization quite literally. I mean, I consider coordination as an essential and common feature of the integration of several brain and bodily processes that present an oscillatory nature, and, as consequence, enact a rhythm. A rhythm ${ }^{10}$ they conform while retaining the capacity to constrain it. This rhythmicity would be one potential aspect of the selfemergent coordinative structures depending on internal and external constraints that Colombetti defended as typical of the embodiment of emotions. In the case of Dewey's theory of emotions, triggering tension would imply straying from the prevalent pattern of coordination. Another type of coordination appears, either because of a conflict between competing chains of actions or because there is no pattern able to entrain the current experience. Whatever the cause, following Dewey's reasoning, I think that an emotion can be understood as a qualitative shift from a more stable state to a more unpredictable, yet still coordinated one, in which there is no rigid automatism between perceptions and actions. According to my hypothesis, this would imply a shift in the prevalence of one coordinative state to another; a change, at least in some sensorimotor circuits, from a state of absolute coordination to another one of relative coordination.

Both concepts come from the field of dynamical systems theory (Kelso 1995), but have been used in enactivism (De Jaegher \& Di Paolo 2007). While in absolute coordination "transitions in the coupling of the systems take place from one stable, perfectly locking state, to another or to non-coordination", in the case of systems in

\footnotetext{
${ }^{9}$ Sensorimotor agency is the precarious self-sustaining network of schemes appertaining to a subject, with an intrinsically perspective, able to engage in intentional actions subservient to her self-generated desires and norms (Di Paolo, Buhrmann \& Barandiaran 2017: 197)

10 My concept of rhythm is that of "an evolving pattern of oscillations able to entrain other oscillations". The reasoning behind this conceptualization as well as a longer characterization can be found in the paper "Rhythm ' $n$ ' Dewey: an adverbialist ontology of art" (Vara Sánchez forthcoming)
} 
relative coordination "[they] do not entrain perfectly. Instead they show phase attraction, which means that they tend to go near perfect synchrony, and move into and out of the zone that surrounds it" (De Jaegher \& Di Paolo 2007: 491). Relative coordination is an emergent property of many behaviors ${ }^{11}$ and systems including normal cortical function ${ }^{12}$, which is characterized by a competition between different components which are not strictly symmetrical, or identical and, for that reason, this coordinative regime is more reactive to smaller disturbances, and does not go back abruptly to a state of equilibrium.

Since emotional episodes are considered to last for seconds to minutes, its rhythmicity, thus, is expected to be a temporal pattern of oscillations that, except in the case of particularly intense episodes or pathological states, has to return to a more stable state in a short time; that is, from relative coordination to absolute coordination. According to Dewey, the struggle of overcoming the disruption between the vegetative-motor and the sensori-motor that underlies an emotion can fail, require some effort or succeed without friction (Dewey 1895: 30). If we think of the patterns of coordination as attractors, in relative coordination, there would be competition between at least two attractors ${ }^{13}$, and the self-emergent dynamics and outcome of an emotion episode would depend on the capacity of these attractors to entrain our behavior and take it back to the well-known road of more stable sensorimotor coordination. Relative coordination can be understood, thus, as a selforganizing dynamic of situations in which our current sensorimotor patterns have to deal with an initial tension that provoke a destabilization that will take time to overcome. Or, in the more cognitivist's words of Bressler and Kelso, "relative coordination [...] provides cortical function with a flexibility that enables it to adapt to cognition's changing contingencies” (2016: 2).

\footnotetext{
${ }^{11}$ Kelso offers the example of a child and an adult walking together. Despite their difference in size, they walk in a coordinated way, thanks to a reciprocal, plastic, relative coordination (Kelso 1995: 98).

${ }^{12}$ It has been proposed that "large scale relative coordination is an emergent property that crucially contributes to cognitive function by metastably integrating and segregating the activities of distributed cortical areas" (Bressler \& Kelso 2016: 4).

${ }^{13}$ This competition could be an example of metastability. This characteristic of a system, according to which minimal changes can affect the precarious equilibrium, has been deemed as typical of sensorimotor coordination patterns (Di Paolo et al. 2017: 102).
} 
This mechanism of relative coordination, I think, is at the same time coherent with Dewey's theory of emotions and an enactive dynamic understanding of cognition. But not only this, it allows to develop a radically embodied view of emotions.

\section{When the body pounds}

Empirical evidence suggests that bodily oscillatory activity gates or modulates sensory perception. Respiratory patterns (Karavaev et al. 2018), gastric basal rhythms (Richter et al. 2017) and heartbeats (Park et al. 2014) affect brain activity in regions and systems dedicated to, among other functions, perception. These and other similar findings sustain the view that " $[\mathrm{t}]$ he body is, in essence, an ensemble of fluctuating systems with biorhythms nested at multiple timescales" (Allen 2019). Physiological and psychological oscillatory patterns can be found along the whole body, influencing each other and enacting a rhythmic hierarchy which is locally different but globally connected.

Furthermore, the heart and the gastric basal system present one relevant peculiarity: both are intrinsic oscillators, able to send bottom-up oscillatory information to the brain; that is, even if totally disconnected from the brain, they are able to continue producing physical contractions and electric activity at precise frequencies. On this line, recent findings "show that visceral signals are coupled with, and sometimes drive, spontaneous brain dynamics, indicating that the viscera and the brain form a single complex system" (Azzalini, Rebollo \& Tallon-Baudry 2019: 505). I consider this to back the claim that perception is always embodied. And embodied not just because of the existence of neuronal pathways constantly modulating brain activity with inputs from body states ${ }^{14}$, but embodied, as well, because oscillatory activity of the body and oscillatory patterns from the brain intertwine to the point of not being able to tell apart where one ends from where the other starts. With every cardiac cycle, the tissue of the optic disc pulsates by the narrowing of the vessels with systole and their dilation with diastole (Jacks \& Miller 2003); the mechanical wave of

\footnotetext{
${ }^{14}$ For a thorough review of the different cortical and subcortical areas, as well as brainstem nuclei that receive inputs from the heart and the gastro intestinal tract see Azzalini, Rebollo \& TallonBaudry 2019.
} 
each cardiorespiratory cycle physically moves and constrains the brain (Holdsworth et al. 2016); the blood flow modifies the temperature in the brain, which, in turn, affects the excitability of brain areas and causes neurons to spontaneously fire (Moore \& Cao 2008). These are examples of oscillatory phenomena in which the body plays an active role in processes that modulate cognition.

The potential impact of these and other examples of bodily driven oscillatory activity upon cognition, in terms of intensity, could be judged as irrelevant in comparison to neural connections ${ }^{15}$. But, in some complex systems, just a slight disturbance is able to provoke a shift from one state to another (Freyer et al. 2012). The same way an overwhelming sense of joy or sadness can be triggered by just a single word or by noticing one, otherwise irrelevant, object, the disturbance causing a shift towards relative coordination can be just a slight increase in temperature on certain brain area or an accelerated heart rate that pumps blood a little bit stronger than before, causing the deviation in the phase of one particular oscillation. That way, the entire circulatory system, along with gastrointestinal tract and respiratory system, are not only a sounding-board that reverberates with every change of consciousness (James 1884: 191), but they themselves actively pound the brain. And they pound it enacting a coordinated rhythmic dialogue that constraints the origin and the dynamics of cognitive processes, and, as a consequence, our engagement with the world. Bodily resonance, as considered by Fuchs, is definitely an extremely important part of this resounding circuit, but I think that we could consider as well a complementary brain resonance, that closes the circuit and reinforces the active role of the body in the enactment of patterns of coordination and offers a view of a full circuit. A coordination, though, able to react to the environment and able to enact different patterns, depending on plenty of factors. One of them could certainly be what Dewey defined as "a certain act of seeing". In the case of an emotional episode, an intentional object could displace or inhibit some coordinating constrain between body and brain for a moment. That modification would be the emotional tension and its evolution in time related to the dynamics of the emotion.

\footnotetext{
${ }^{15}$ This could be the case, but, for example, Richter et al. defend that about the $8 \%$ of the alpha amplitude fluctuarions in the brain is driven by gastric waves (Richter et al. 2016).
} 


\section{Conclusion}

Brain and body elements of non-neural nature are necessary elements for the proper functioning of cognitive processes and our engagement with the world. The physical rhythm enacted by these oscillatory components favors some resonant frequencies, but, except for pathological cases, it reacts both to external and internal constraints. John Dewey defends that an emotional episode starts with a tension. I think that this tension is a transition to more unstable coordinating states of oscillatory activity between the brain and the body. That is, whatever the triggering of this tension is, it will necessarily be enacted by a change in some patterns of coordination in oscillatory activity. There is no brain phase and then, afterwards, a bodily phase of emotions, or the other way around. An emotion is, from the moment it starts, an experience of tension between brain and body based processes. I am not saying that an emotion is only a rhythmic change, but that it necessarily presents a different rhythmic coordination that takes some time to be overcome. The role of the body in the embodiment of emotions, thus, is not only sending interoceptive information to the brain, triggering movements that condition our engagement with the environment, or bodily resonance; it plays, as well, an active part on the rhythm that enacts along brain oscillations. And this should not be overlooked.

In conclusion, I think that an emotion can be regarded as a temporary coordinative structure that emerges when a tension is able to disrupt some oscillatory pattern enough to displace the sensorimotor connections, constantly enacted and homeostatically maintained, to a state of relative coordination, which is characterized by a tension between attractors able to compete to entrain our sensorimotor patterns. An emotion, therefore, in my opinion is necessarily and radically embodied and with the body playing an active role. The rhythm counterpoint enacted in an emotional episode is played at four hands together by the body and the brain. 


\section{Bibliography}

ALLEN, M. et al. In the Body's Eye: The Computational Anatomy of Interoceptive Inference. bioRxiv, 2019. DOI: http://dx.doi.org/10.1101/603928

AZZALINI, D., REBOLLO, I. \& TALLON-BAUDRY, C.T. Visceral Signals Shape Brain Dynamics and Cognition. Trends in Cognitive Science. 23, 8, 488-509, 2019.

BRESSLER, S. L. \& KELSO, J. A. S. Coordination Dynamics in Cognitive Neuroscience. Frontiers in Neuroscience, 10, 397, 2016. DOI: https://dx.doi.org/10.3389/fnins.2016.00397

CANDIOTTO, L. Emotions. In: PETERS, M.A (ed.) Encyclopedia of Educational Philosophy and Theory. Singapore: Springer, 2016. DOI https://doi.org/10.1007/978-981-287-532-7_311-1

COLOMBETTI, G. The feeling body: Affective science meets the enactive mind. Cambridge, MA: MIT Press, 2014.

DE JAEGHER, H. \& DI PAOLO, E. Participatory sensemaking: An enactive approach to social cognition. Phenomenology and the Cognitive Sciences, 6, 4, 485-507, 2007.

DEWEY, J. The Theory of Emotion. (1) Emotional Attitudes. Psychological Review, 1, 553$569,1894$.

DEWEY, J. The Theory of Emotion (2) The Significance of Emotions. Psychological Review, 2, 13-32, 1895.

DEWEY, J. The Reflex Arc Concept in Psychology. Psychological Review, 3, 357-370, 1896.

DI PAOLO, E., BUHRMANN, T. \& BARANDIARAN, X. E. Sensorimotor Life: An Enactive Proposal. Oxford University Press, 2017.

DREON, R. Fuori dalla torre d'avorio: L'estetica inclusiva di John Dewey oggi. Genova-Milano: Marietti, 2012.

DREON, R. A Pragmatist View of Emotions: Tracing Its Significance for the Current Debate. In: CANDIOTTO, L. (ed.) The V alue of Emotions for Knowledge. Basingstoke: Palgrave Macmillan, 2019. 71-99. DOI https://doi.org/10.1007/978-3-030-15667-1

FREYER, F. et al. A Canonical Model of Multistability and Scale-Invariance in Biological Systems. PLOS Computational Biology, 8, 8, e1002634, 2012.

FUCHS, T. The phenomenology and development of social perspectives. Phenomenology and the Cognitive Sciences, 12, 655-683, 2013.

FUCHS, T. \& KOCH, S. Embodied Affectivity: on moving and being move. Frontiers in Psychology, 5, 508, 1-12, 2014.

FUCHS, T. Intercorporeality and interaffectivity. Phenomenology and Mind, 11, 194-209, 2016.

FUCHS, T. Ecology of the Brain. Oxford: Oxford University Press, 2018.

GALLAGHER, S. Enactivist Interventions: Retbinking the Mind. Oxford: Oxford University Press, 2017. 
GALLAGHER, S \& ALLEN, M. Active inference, enactivism and the hermeneutics of social cognition. Synthese, 195, 6, 2627-2648, 2018.

GARRISON, J. Dewey's Theory of Emotions: The Unity of Thought and Emotion in Naturalistic Functional 'Co-ordination' of Behavior. Transactions of the Charles S. Peirce Society 39, 3, 405-443, 2003.

HOLDSWORTH, S. J. et al. Amplified magnetic resonance imaging (aMRI). Magnetic Resonance in Medicine, 75, 6, 2245-2254, 2016.

HUSSERL, E. Ideas pertaining to a pure phenomenology and to a phenomenological philosophy II. Dordrecht: Kluwer, 1989.

JACKS, A. S. \& MILLER, N. R. Spontaneous retinal venous pulsation: aetiology and significance. Journal of Neurology, Neurosurgery, and Psychiatry, 74, 1, 7-9, 2003.

JAMES, W. What is an emotion? Mind, 9, 188-205, 1894.

JAMES, W. The principles of Psychology. New York: Henry Holt and Company, 1890.

KARAVAEV, A.S. et al. Synchronization of infra-slow oscillations of brain potentials with respiration. Chaos: An Interdisciplinary Journal of Nonlinear Science, 28, 8, DOI: https://doi.org./10.1063/1.5046758.

KELSO, J. A. S. Dynamic patterns: The self-organization of Brain and behavior. Cambridge, MA: MIT Press, 1995.

MOORE, C. I. \& CAO, R. The hemo-neural hypothesis: on the role of blood flow in Information processing. Journal of Neurophysiology, 99, 5, 2035-2047, 2008.

O'REGAN, J. K., NOË, A. A sensorimotor account of vision and visual consciousness. Behavioral and Brain Sciences, 24, 939-1011, 2001.

PARK, H. D. et al. Spontaneous fluctuations in neural responses to heartbeats predict visual detection. Nature Neuroscience, 17, 612-618, 2014.

RICHTER, C. G. et al. Phase-amplitude coupling at the organism level: the amplitude of spontaneous alpha rhythm fluctuations varies with the phase of the infra-slow gastric basal rhythm. NeuroImage. 146: 951-958, 2017.

THOMPSON, E. Mind in life: Biology, phenomenology, and the sciences of mind. Cambridge, MA: Harvard University Press, 2007.

VARA SÁNCHEZ, C. Rhythm 'n' Dewey: an adverbialist ontology of art. Rivista di Estetica (forthcoming)

VARELA, F. J., THOMPSON, E., \& ROSCH, E. The embodied mind: Cognitive science and human experience. Cambridge, MA: MIT Press, 1991. 